\title{
Exhumación informática en el Archivo Daniel Moyano. Una reflexión sobre soportes, materialidades y el devenir de originales y borradores*
}

Fecha de recepción: 10 de mayo de 2016

Fecha de aprobación: 30 de agosto de 2016

\section{Resumen}

El trabajo aborda nociones centrales en torno a los archivos de escritores a partir de una experiencia llevada a cabo en el Archivo Virtual Daniel Moyano: la recuperación de textos a partir de un dispositivo informático obsoleto. Textos que Moyano conservó en soportes de almacenamiento hoy inaccesibles y que logramos recuperar, en un trabajo conjunto entre el CRLA-Archivos (Francia) y la Universidad Nacional de Córdoba (Argentina). Desde un enfoque hermenéutico, la exhumación informática permitió articular con estos documentos la génesis de los procesos de ficcionalización del autor, no restringidos a textos que podrían pensarse a primera vista como literarios, con una reflexión sociotécnica sobre esas prácticas, que ha inspirado interrogantes sobre cómo ha mutado el lugar de la técnica en la relación entre arte y sociedad.

Palabras clave: Daniel Moyano, archivos virtuales, análisis hermenéutico de obras, exhumación informática, originales y copias.

Citar: Vigna, D. (julio-diciembre de 2016). Exhumación informática en el Archivo de Daniel Moyano. Una reflexión sobre soportes, materialidades y el devenir de originales y borradores. La Palabra, (29), 139-158. doi: http://dx.doi. org/10.19053/01218530.n29.2016.5707

\section{Diego Vigna}

CONICET-Universidad Nacional de Córdoba. diegovigna@ gmail.com.

* Artículo de reflexión. Proyecto «La memoria de los archivos en la recuperación de obras: versiones, reescrituras e inéditos ocultos del escritor argentino Daniel Moyano (1930-1992)», Programa Bernardo Houssay MESR (Francia) - CONICET. 


\section{la palabra}

\section{Computer Exhumation in the Daniel Moyano Virtual Archive. A Reflection about Writing Formats, Materiality and the Evolution of Originals and Drafts}

\section{Abstract}

This paper addresses central notions concerning writer's archives, based on an experiment conducted in the Daniel Moyano Virtual Archive: the recovery of texts from an outdated computing device. These texts were preserved by Moyano in a storage media inaccessible for present times, and were recovered in a joint effort between the CRLA-Archives (France) and the National University of Cordoba (Argentina). From a hermeneutical perspective, computer exhumation of these documents allowed us to articulate the genesis of the author's processes of fictionalization -not restricted to texts considered literary at first glance- with a socio-technical interrogation about these practices. This has inspired questions about the transformation of role of technique, particularly in the relation between art and society.

Keywords: Daniel Moyano, virtual archives, hermeneutic analysis, computer exhumation, originals and drafts.

\section{Exhumation informatique dans l'Archive de Daniel Moyano. Une réflexion sur les supports, matérialités et le devenir des originaux et des brouillons}

\section{Résumé}

Cet article présente des notions sur les archives d'écrivains à partir de l'expérience de retrouver des textes dans l'Archive Virtuel Daniel Moyano, un dispositif informatique désuet. Il s'agit de textes que Moyano a conservé dans des supports de stockage aujourd'hui inaccessibles et qu'on a réussi à retrouver grâce au travail que nous avons réalisé en partenariat avec le CRLA-Archives (France) et l'Université Nationale de Córdoba (Argentine). D'un point de vue herméneutique, l'exhumation informatique des documents a permis de repérer, d'une part, une volonté de construction de fictionnelle de la part de l'auteur à partir de textes qui peuvent être classifiés comme non littéraires. D'autre part, on a construit une réflexion sociotechnique sur ces pratiques qui nous a permis de nous demander de quelle manière la place de la technique et de son rapport à l'art et à la société s'est transformé.

Mots-clés : Daniel Moyano, archives virtuels, analyse herméneutique des œuvres, exhumation informatique, originaux et brouillons. 


\section{Introducción}

Este trabajo tiene como cimiento la explotación científica que lleva a cabo un equipo de investigadores en torno a la multifacética obra del escritor argentino Daniel Moyano (1930-1992). La creación del Fondo Documental Moyano en 2008, en el Centre de Recherches Latino-américaines (Poitiers, Francia), propició el desarrollo de un vínculo institucional entre investigadores que derivó en la creación del Archivo Moyano en 2009, y luego en importantes trabajos conjuntos. Entre ellos, la edición crítica en 2012 de la novela Tres Golpes de Timbal (1989) en la Colección Archivos del CRLA, y la creación del Archivo Fotográfico del autor. En este marco, abordamos un nuevo estadio en la evolución del Archivo Moyano, desde los estudios críticos y genéticos. Como en cada proyecto realizado, partimos del análisis de las conexiones existentes entre los distintos documentos que conservó Moyano en sus distintas etapas de producción: textos de ficción (papeles, manuscritos, libros editados), fotografías, correspondencia, textos periodísticos, apuntes o recortes.

Nos dedicaremos a problematizar nociones centrales en el trabajo con archivos a partir de una singular experiencia llevada a cabo en 2015: la recuperación de archivos de texto a partir de un dispositivo informático ob- soleto, textos que Moyano tipió y conservó en soportes de almacenamiento casi inaccesibles en la actualidad, y que hemos logrado recuperar para luego migrar los datos a los soportes y formatos informáticos vigentes. Este es el inicio del aporte hermenéutico surgido de la naturaleza de los documentos, en el marco de un archivo heteróclito: nuestro objetivo es analizar específicamente la correspondencia exhumada para mostrar, por un lado, aspectos de la rutina de creación y de la incidencia del avance técnico en esta; y, por otro lado, dar cuenta de cómo la palabra inscripta del autor se constituye como ejemplo del proceso de transición entre la cultura impresa y la cultura digital. En este sentido, como fruto de la constatación empírica, esta experiencia de exhumación informática ha inspirado interrogantes sobre cómo y de qué formas ha mutado el lugar de la técnica (renombrada en tecnología[s] durante el siglo XX [Cabrera, 2006]) en la relación entre arte y sociedad.

El conocimiento de la génesis de una obra, desde el punto de vista del análisis literario y desde la base de la experiencia inscrita en diversos textos, tanto por el autor como por el investigador, permite abordar las dimensiones de una producción particular y, a su vez, establecer un diálogo con la época, según el contexto de producción. En este sentido, la intervención de cualquier investigador que implica inventariar y organizar los documentos de un escritor conlleva decisiones metodológicas insoslayables para sistematizar un abordaje crítico-genético, y de ese modo proponer el diálogo que recupera el pasado, o una versión de este, desde el presente de la intervención, casi a la manera de la arqueología convencional.

El abordaje hermenéutico permite articular la génesis de los procesos de ficcionalización del autor, no restringidos a los documentos que podrían pensarse a primera vista como literarios, con una reflexión socio-técnica de esas prácticas. Dicha reflexión se expande por la experiencia singular del archivo y va más allá del objeto. Con la exhumación informática que realizamos, es posible repensar las formas que ha admitido el progreso técnico según los discursos de época y las experiencias subjetivas, en el marco de la escritura creativa; y ver cómo las paradojas brotan a medida que, desde el presente, indagamos las construcciones de un porvenir que en cada momento histórico toma formas particulares, sea del encantamiento tecnológico o del presagio sobre las facilidades de toda nueva era.

La sospecha que guía este trabajo podría expresarse en un interrogante con cierto efectismo: ¿el futuro nos devolverá siem- 
pre al papel? En la discusión sobre la vigencia, estabilidad y utilidad de los soportes y formatos de publicación y almacenamiento de la producción artística y literaria, el primer intento de respuesta, en el contexto del trabajo con archivos, es que siempre será necesario acudir al soporte más estable para poder dar aval de porvenir (Derrida, 1997) a los futuros arqueólogos de la palabra y el pensamiento. Pero, además, esta sospecha se nutre con la singularidad del caso Moyano, y despliega un potencial exploratorio más amplio: la posibilidad de indagar cómo los cambios informáticos, inscritos en numerosos archivos de texto que quedaron latiendo en viejos disquetes olvidados (nos limitaremos al análisis de la correspondencia epistolar), dan cuenta no solo del método creativo del autor, se trate de pre-textos preparatorios o material redaccional ${ }^{1}$ (Lois, 2001, p. 3), sino también del éxito de un discurso tecno-instrumental basado en la innovación y la eficiencia que llevó a pensar en la aparición de nuevas formas de la memoria, de nuevas formas de estabilidad a la hora de escribir desde los dispositivos informáticos, de ventajas técnicas para combatir la evanescencia de la imaginación.

El diseño metodológico, siguiendo a Lois (2001), se enfocó en la materialidad y las formas que asume la escritura, en este caso a partir del cotejo de pre-textos preparatorios, pre-textos redaccionales (ambos recuperados de los disquetes) y también versiones establecidas. Ofrecemos un recorte a partir de las cartas recuperadas y algunos textos publicados. El análisis se basó en la confrontación escritura-texto que permite integrar a la génesis de escritura fenómenos más amplios de génesis y estructura de otros campos (Lois, 2001, p. 4).

\section{El autor: vida, obra, y la hete- rogeneidad de los documentos del archivo}

La singularidad del archivo Moyano remite no solo a su composición: su recorrido vital, nutrido de tantos infortunios y opacidades como de anécdotas y curiosidades, explica las múltiples facetas que se han involucrado en su legado artístico y humanista, que como dijimos no se restringe a la producción literaria.
Moyano nació en Buenos Aires en 1930, pero transitó casi toda su vida entre viajes y mudanzas, primero en el interior de la Argentina y luego en su exilio en España, hasta su fallecimiento en 1992. Por episodios ajenos a su voluntad, la mayor parte de esas mudanzas fueron obligadas. Entre tantos movimientos, forjadores de una inquietud que nunca habría de abandonar, Moyano pasó sus años de juventud en la provincia de Córdoba (Argentina), donde comenzó a rodearse de escritores y personalidades cercanas al universo de la producción artística. Gracias a esos vínculos, y a su cualidad autodidacta, consolidó allí su formación intelectual, aunque fue hacia fines de la década de 1950 cuando una nueva mudanza marcó el comienzo de su etapa más fructífera desde el punto de vista artístico y existencial: su llegada a La Rioja (Argentina), donde residió hasta 1976.

Allí comenzó sus tareas como periodista, a la par de su producción literaria; fue corresponsal del diario Clarín entre 1961 y 1976. Allí profesionalizó también su condición de músico, al convertirse en profesor de violín e intérprete de viola. En La

Utilizamos la definición de Élida Lois (2001) para esta distinción: tomamos como material pre-redaccional, o pre-textos preparatorios, a todo documento anterior al proceso de textualización: planes, argumentos, guiones. Mientras que el material redaccional, o pre-textos propiamente dichos, refieren a la escritura ya encaminada a textualizar: borradores, estadios textuales sucesivos, copias en limpio, pruebas de imprenta (p. 3). Lois no desecha híbridos entre estas definiciones.

2 En 1964, el prólogo que escribió Augusto Roa Bastos a La lombriz habría de marcar su trabajo desde toda lectura crítica. En 1966, Sudamericana publicó la novela Una luz muy lejana, traducida al francés, y en 1967 publicó El fuego interrumpido (cuentos). Ese mismo año Moyano recibió el Premio Primera plana por su novela El oscuro, que Sudamericana publicó en 1968. 
Rioja escribió gran parte de su obra de ficción, y en esos años sus libros comenzaron a obtener un reconocimiento que luego se tradujo en publicaciones y premios $^{2}$. Asimismo, además de sus facetas como escritor, músico y periodista, Moyano tradujo su inquietud para el registro de gestos, detalles y mundos ignorados en un corpus de más de 4000 fotografías que, oculto en su biblioteca personal, al igual que los 25 disquetes que conforman nuestro objeto de estudio, permitió conocer otra arista de su registro creativo: un corpus desconocido sobre su búsqueda poética y su labor periodística, centrado mayormente en ese período de su vida en el que tuvo contacto cotidiano con el interior argentino. Ese descubrimiento nos permitió comprender que las fotos forman parte, junto a los textos periodísticos y literarios, de un mismo universo expresivo.

La etapa riojana culminó abruptamente con el golpe de Estado del 24 de marzo de 1976. Moyano fue encarcelado por las fuerzas ilegales y, luego de algunas semanas, liberado e inducido a abandonar el país. Así comenzó la etapa del exilio en
Madrid, que se extendió hasta su muerte. En los primeros años de exilio, dijo sentir el desarraigo y una suerte de vaciamiento espiritual y artístico; abandonó todo sensibilidad poética y dijo haber perdido su voz y, de ese modo, el lugar simbólico de la escritura (Casarin, 2012). Sin embargo, ese proceso que marcó su cotidianeidad y la de su entorno, y que tardó varios años en devolverlo al entusiasmo de la escritura, fue el germen de lo que luego se constituyó como uno de los rasgos más singulares de la «segunda parte» de su obra narrativa: por un lado, el impulso obstinado de recuperar el tiempo perdido en la escritura, materializado a partir de un quiebre en la factura de sus textos que tendió hacia un proyecto literario mucho más musical $\mathrm{y}$, podríamos decir, barroco con el uso del lenguaje, y a una simbolización creciente de todo referente involucrado en las tramas. Por otro lado, la ejecución de un plan de reescritura que nació, como veremos, con la asimilación de los procesadores de texto informáticos, y luego se convirtió en un plan programático dedicado a revisar todo lo escrito en su lejana patria. Lo primero ha quedado impreso en una serie de novelas donde el exilio, el autoritarismo y el retorno a las fuentes se hermanan con el contexto latinoamericano, encauzadas en un tratamiento musical ${ }^{3}$. El mismo Moyano lo expresó en una de las cartas encontradas, dirigida a su amigo César Llanos: «[...] dejé de tocar para siempre. Me desquito escribiendo como si tocara o compusiera $[\ldots]\rangle\rangle^{4}$. Lo segundo, el plan de reescritura, ha dejado huellas en los archivos de texto recuperados de los disquetes Amstrad, pero también en su biblioteca: las mismas hojas de sus libros editados y conservados junto a esos disquetes a los que nadie atendió hasta 2014, exponen sus anotaciones y correcciones manuscritas.

Esto introduce el objeto que nos incumbe, en lo que fue el período más intenso de su trabajo en Madrid. Inquieto a la hora de poner en práctica nuevos métodos de expansión de la imaginación y, por tanto, de la palabra, esto también incluyó a su relación con los dispositivos de escritura. Moyano fue mejorando sus herramientas a medida que la economía se lo permitía, y la irrupción informática, encauzada en el consumo de ordenado-

3 Esto se aprecia en las novelas El trino del diablo y otras modulaciones (1988), Libro de navíos y borrascas, El vuelo del tigre y quizás su texto más complejo: Tres golpes de timbal (1989).

4 Moyano amplía esto con una referencia directa a su obra: la carta dice «También para mí, que me pasé lijando plásticos en una fábrica los primeros siete años del exilio, y dejé de tocar para siempre. Me desquito escribiendo como si tocara o compusiera, mi última novela se llama Tres golpes de timbal y está llena de músicos andinos, pero me temo que no la lea nadie, salvo algún músico que descubra que las palabras también pueden ser notas musicales. Está inédita, los editores la están leyendo pero no la entienden, pese a que les he explicado que para entenderla bien hay que oír muchas veces las 'Variaciones Goldberg' de J.S. Bach» (Archivo Virtual Moyano, Archivo Amstrad. 4-1-1988. Referencia: [Correspondencia/ Amigos/Disco 10/llanos.001]). 
res personales, lo llevó a «alfabetizarse» con los primeros procesadores de texto lanzados al mercado. Recuperaremos entonces las huellas de lo que implicó el surgimiento de nuevas experiencias creativas, nacidas de ese momento de quiebre para las rutinas de producción. Pero antes, volvemos al sustento teórico de estas experiencias desde la pregunta-eje: ¿qué son los archivos de escritores, y cómo ha sido el devenir en la construcción de este objeto desde la hegemónica cultura impresa hasta la irrupción actual de la cultura digital, que ha logrado semejante incidencia en todos los ámbitos de la vida social, económica, artística y científica?.

La noción de archivo y la problemática de la digitalización desde una mirada crítico-genética

El trabajo con archivos de escritores se despliega en un terreno multidisciplinar; involucra a la archivística, por lo que implica el trabajo específico con los documentos en pos de su organización, conservación $\mathrm{y}$ consulta, y también intervenciones enmarcadas por la crítica genética, «esa "porción" de los estudios literarios que postula el estudio de los manuscritos modernos como un modo de acceder desde otro lugar, con otra mirada, al proyecto creador de un escritor» (Goldchluk y Pené, 2013, p. 7). La definición específica del objeto tiene que ver con lo que implica organizar y analizar documentos que conforman un archivo personal de literatura (Pené, 2013). En este sentido, la definición que ofrece Pené habla de un conjunto organizado de documentos, más allá de las fechas, formas y soportes involucrados, que fue generado y reunido de modo arbitrario por un escritor y conservado por el creador o sus sucesores para sus propias necesidades, «o bien remitidos a una institución archivística para su preservación» (Pené, 2013, p. 29). Esta definición se asienta en la mirada archivística. Pero, para contemplar la mirada geneticista (la cuestión literaria y su contexto de producción), es necesario acudir a la singularidad y las posibles reverberaciones de las experiencias escriturales. Así como puede arriesgarse una definición conceptual abarcadora sobre qué es un archivo de escritor, es también complejo dar cuenta de las vicisitudes que se involucran en esto desde el origen mismo del acto de escritura. Eso que Gerbaudo analizó, desde los conceptos de Derrida, como las condiciones para que haya archivo. Primero, desde lo que implica «hacer archivo» para el escribiente; después, desde lo que implica «hacer archivo» en la explotación científica de una obra, en el ambiente técnico actual.

Según Derrida, las condiciones para que haya archivo pueden comenzar a discutirse desde la misma instancia en que algo se «deposita en una exterioridad»; no habría archivo si no hay conservación en algún soporte, por fuera de la memoria humana (Derrida, 2013, p. 209). De allí nacen las dos aristas que Derrida menciona como primer predicado para la existencia de archivo: topografía y exterioridad. Esto propone un estadio anterior a la definición que compartimos desde la archivística: el gesto inicial de cualquier autor, desde este punto de vista, es previo a la constitución de un conjunto organizado de documentos, intervenidos y organizados. El gesto de un autor, por más espontáneo que sea, de consignar en un lugar exterior su palabra, implica una selección y un ejercicio de poder, previo a cualquier operación crítica de selección e interpretación ejecutado por un archivero (Derrida, 2013). Para Derrida, hay archivo desde los pre-textos más iniciales, en el universo íntimo del autor y en el deseo mismo de "poner fuera» la palabra; esto es, en el deseo de la consignación en un soporte, donde se debatirían impulsos que tienden lazos desde la estructura psíquica del sujeto a la estructura posible del archivo: es la contradicción inherente del ser lo que fundamentaría el hacer. Según Derrida, hay archivo en diferentes niveles: comprendemos mejor el archivo en el sentido convencional, con la interpretación de las autoridades que archivan, pero su condición de posibilidad es previa, desde que hay «un depósito aparentemente calculado» en una exte- 
rioridad (Derrida, 2013, p. 211). Y la contradicción es inherente al proceso, porque el deseo del escribiente es contradictorio: por un lado, no habría deseo de archivo sin la finitud radical, sin la posibilidad de pérdida y de olvido; Derrida corona esto con la frase «escribo para guardar» (p. 76). Por otro lado, el escribiente tiene ganas de proteger la originalidad de su texto, pero sobre todo «tiene ganas de no protegerlo»; ganas de que sea robado. "Cuando firmamos, queremos ser robados, y que el ladrón guarde la firma arrebatada», (pp. 222-223).

Si esto comienza con la primera lectura, hecha por el mismo escribiente, el interviniente-archivista no hace más que firmar sobre la firma del autor (Derrida, 2013). Es la pulsión de archivo lo que redefine, ahora sí desde la archivística, porque es tan importante en la actualidad lo que se denomina domiciliación. El acto que «arranca al objeto de su entorno primordial y establece la distancia desde donde se realiza la interpretación»» (Goldchluk, 2013, p. 34).

\section{La domiciliación, los archivos} virtuales y la noción de original

La historia de la creación y la explotación científica de archivos se ha visto repercutida por la digitalización de documentos, como cualquier otra actividad artística, cultural o científica; toda reflexión teórica y metodológica se amplió con estas prácticas. La posibilidad de reproducir digitalmente textos, imágenes, audios y videos reconfiguró las escenas de domiciliación; allí donde haya un ordenador puede haber un nuevo archivo, con capacidades abismales de almacenamiento (Goldchluk, 2013). Esto cambió el horizonte de las disciplinas, como su repercusión social, porque a pesar de que la reproducción de documentos valiosos para su conservación y consulta «es una constante desde los copistas medievales hasta el desarrollo del microfilme», ninguna tecnología precedente «había roto la identificación entre espacio físico e institucional» (Goldchluk, 2013, p. 35). Chartier (2001) lo enunció en sentido más general: el universo digital permitió discutir la asociación inmediata entre soporte y contenido.

Hacer archivo, en este marco, deja de estar ligado a la necesidad de «tener los manuscritos» (Goldchluk, 2013, p. 48). La domiciliación digital, deslocalizada, ofrece un espacio virtual donde se organizan y ofrecen máscaras: imágenes de documentos que pueden estar distantes en su materialidad, aunque próximos y articulados en una pantalla. Esto, a su vez, interpela la discusión sobre esa oferta de materiales a los que se puede acceder desde cualquier ordenador: en el ambiente de la reproducción digital, que exa- cerbó hasta un grado impensado el pronóstico benjaminiano de la primera mitad del siglo $\mathrm{XX}$, la amenaza de la adulteración y la diseminación descontrolada han llevado a discutir las categorías de original y copia, que a primera vista resultarían caducas. Según Goldchluk, el incierto origen de la escritura marca la paradoja entre «lo único y lo seriado», pensando en términos del objeto que representa ese origen: el original o manuscrito para los geneticistas. Con la popularización de los procesadores de textos informáticos, y con la posterior irrupción de las redes de información, esto se expandió en forma inquietante: si desde ya todo manuscrito se debate entre el acontecimiento único que significa el nacimiento de un trazo, que es el registro, y el acontecimiento que implica ese acto de registrar (su iterabilidad [Goldchluk, 2013, p. 41]), las posibilidades de digitalizar y reproducir en red cualquier tipo de documento, haya sido elaborado en el soporte que fuere, serían ilimitadas en el sentido de la visibilización resultante.

Sin embargo, la experiencia de exhumación informática se inserta entre los filamentos de esta problemática. La sociedad de consumo, sostenida en la lógica del reemplazo veloz de dispositivos que aceptamos en pos de nuevas velocidades, funcionalidades, en definitiva, de los llamados «progresos» técnicos, no fomentan la reflexión sobre qué 
sucede con los soportes y dispositivos obsoletos, y por tanto con la preservación de productos intelectuales y artísticos que así parecen restringidos no a la generación, sino a la pérdida del secreto. Desde los interrogantes involucrados en estas prácticas, hoy nos encontramos con dispositivos informáticos que han quedado en una suerte de limbo: han servido para crear documentos digitales, almacenados en soportes informáticos, pero esos soportes y documentos ya no son legibles ni trasladables a dispositivos y software vigentes. Las categorías, entonces, de original y copia pueden pensarse caducas con las salvedades de cada contexto: otra pregunta, posterior a la sospecha inicial, afina la paradoja. Un texto que nació digital, arrumbado en un disquete obsoleto, ¿opera como original, antes de cualquier proceso de recuperación?

Fernando Colla (2010; 2013) conjugó las dificultades que se involucran en la administración de archivos virtuales, y que atañen tarde o temprano a todo documento digital: todo documento es tributario del formato que lo codifica y del sistema operativo que lo torna legible en una pantalla. De hecho, los avances de la última década a manos de editores, bibliotecarios, archivistas e informáticos en pos de garantizar el acceso a los documentos a partir de protocolos de codificación abiertos, «independientes de todo programa y sistema operativo creado por sociedades comerciales», son una respuesta a la cada vez más veloz sustitución de versiones que las empresas informáticas lanzan al mercado (Colla, 2013, p. 112). La superación de una generación de dispositivos por otra pone en peligro el acceso libre, ya que uen caso de desaparición de un tipo de lector, los documentos almacenados se vuelven inaccesibles, del mismo modo que la interrupción de la producción de un soporte vuelve a los aparatos inútiles» (Colla, 2013, p. 113). Según Colla, las nuevas políticas pueden liberar al archivista de la tiranía técnico-mercantil, pero no garantizan la perennidad de las informaciones. Esto es central porque siempre reubica a la materialidad como terreno perimido u obsoleto, pero a la vez seguro, como soporte que representaría cierto ¿anacronismo?, no obstante, de una estabilidad ajena a los movimientos actuales del mercado, como lógica proveniente de otra medida del tiempo. El papel puede provenir del pasado más remoto y hacerse presente de inmediato, a diferencia de las especulaciones entre hardware y software.

Esto se puede corroborar con el caso Amstrad, en el archivo Moyano. Pero no es el único corpus que, como afirma Colla, ha quedado inutilizable por causa de los programas y formatos con que han sido realizados. Incluso la memoria se involucra de lleno en esto: los dispositivos informáticos almacenan los datos en soportes físicos, aun aquellos que consultamos en Internet. Todo lo virtual descansa a oscuras en una materialidad concreta, pasible de sufrir desperfectos.

Si, como afirma Derrida, todo archivo es en su origen incompleto y transitorio, la condición digital ha reactualizado ese «permanente peligro» que se vuelve constitutivo del deseo de archivar. La singularidad del archivo Amstrad de Daniel Moyano, en este contexto, brinda un eslabón más en la reflexión sobre manuscritos y originales. Planteamos la pregunta sobre si un texto que nació digital, y que se volvió secreto en un disquete obsoleto, puede operar como original, es decir, como si fuera un manuscrito. Antes de esa respuesta, debemos decir que en nuestro objeto de estudio el manuscrito es, primero, el soporte. Antes de pensar si lo es el documento.

\section{La exhumación del Archivo Amstrad y el epistolario en- contrado}

Moyano compró en 1987 un ordenador Amstrad PCW8512, que utilizó con fruición durante los siguientes dos años. En 1987, una nueva practicidad estaba encarnada en la aparición de los dispositivos informáticos como superación de los mecánicos: el modelo 8512 se carac- 
terizaba por incluir de fábrica el procesador de textos Locoscript, quizás el primer programa popularizado para esos fines en ordenadores domésticos. A su vez, el Amstrad incluía dos unidades de disco, teclado e impresora. Para alguien dedicado a la escritura, estos avances eran notables en términos de eficiencia: como indicó Moyano en cartas dirigidas a amigos y colegas, el teclear informático significó poder corregir en el mismo proceso escritural, allí donde antes tenía que aplicar un corrector o directamente comenzar de nuevo el tipeado.

El Amstrad hoy es una pieza de colección: no puede ser conectado a ninguna red, y ofrece obstáculos para migrar los datos a un software actual (por ejemplo, un software que permita la migración del Locoscript a un formato Word). El rescate del material almacenado en los disquetes solo puede efectuarse a través de un especialista que conserve un Amstrad, sea para reproducir los textos en pantalla e imprimirlos (es decir, producir originales en papel) o para migrar los datos con un software y recuperar los textos en un formato actual. Es decir, producir originales también, para los geneticistas, aunque los textos puedan ser reproducidos e impresos a discreción.

Moyano conservó borradores, versiones previas de libros, correspondencia con amigos, familiares y colegas, artículos periodísticos, canciones, poemas, apuntes. El primer reconocimiento del material dio cuenta de 22 disquetes que fueron separados por tener rótulos relacionados con la obra literaria ${ }^{5}, \mathrm{y}$ otros 23 que contienen software para el ordenador. El estado de los disquetes fue una de las claves de la exhumación, ya que permanecieron en perfecto estado durante 30 años. Según el testimonio de la familia, esto se debió a que nadie se interesó por ellos hasta el presente. Eso nos permitió comenzar el proceso de recuperación de los disquetes, que dio como resultado 715 archivos de texto.

Luego de la conversión a un formato legible, inventariamos los archivos a partir del principio de procedencia. Después, los organizamos siguiendo la lógica implementada en el Archivo Virtual Moyano, con la siguiente organización: Versiones completas / Versiones parciales
/ Cuentos reescritos / Cuentos sueltos; Cuentos inéditos / Artículos / Retazos, comienzos, apuntes y reflexiones de lectura / Poesía / Correspondencia.

Aquí, analizamos la correspondencia exhumada ${ }^{6}$ para mostrar dos aspectos de la rutina de creación, y de la incidencia del avance técnico en esta. Primero, partiendo de algunos interrogantes: ¿puede considerarse al archivo epistolar como parte de los originales literarios, es decir, como textos que han tenido incidencia en el proceso escritural como los borradores de cuentos y novelas? ¿Puede considerarse a las cartas como material pre-redaccional? Esto para mostrar cómo en las cartas se encuentra también el germen narrativo; cómo fue que, cautivado por las posibilidades técnicas, trasladó su entusiasmo al mecanismo de escritura. Segundo, dando cuenta de cómo la palabra de Moyano en las cartas se constituye como ejemplo de lo que fue el proceso de transición, tan notable para los estudios literarios y culturales, entre la cultura impresa y la cultura digital, con sus fantasías y expectativas.

$5 \quad$ En las anotaciones de los disquetes hay referencias a novelas: Tres Golpes de Timbal l-Il Versión definitiva, El trino del diablo, En la atmósfera; y otras relacionadas con cuentos: Cuentos rescritos, La lombriz y otros cuentos, Musicalia, María violín, Halcón verde y la flauta maravillosa, etc. También encontramos el rótulo "Cartas", cuyos contenidos son de vital importancia para esclarecer el recorrido escritural y editorial del autor.

$6 \quad$ Antes de los disquetes, la correspondencia del autor en el archivo se restringía a las cartas recibidas en papel, conservadas en Madrid, y unas pocas de su autoría donadas por terceros. 
Humanización y ficcionalización de la máquina y el descubrimiento de nuevas formas de pretextualización

Seguimos con una pregunta que Gerbaudo recogió de Miguel Dalmaroni, acerca de la obra del escritor argentino Juan José Saer y de las dimensiones que puede incorporar un archivo: ¿dónde empieza y dónde termina una obra? Así como hemos analizado las conexiones existentes entre las fotografías, los textos periodísticos y las ficciones de Moyano (Vigna, 2015), la exhumación de las cartas tipiadas en el Amstrad refuerza la evidencia de que todo archivo es inestable, y que toda conformación de un conjunto de documentos literarios va más allá de los manuscritos convencionales, fetiches para la genética textual, e involucra diversas textualidades y lenguajes. La pregunta de Dalmaroni se complejiza al analizar las cartas de Moyano, ya que estas resuelven misterios interpretativos que los manuscritos literarios no habían podido resolver. La esfera más íntima de su archivo amplía la esfera literaria desde las obsesiones personales y las condiciones sociales y políticas de producción.

En el camino a la humanización de la máquina, encontramos una carta dirigida a Lene (16-
11-1987) en la que Moyano escribía caracteres en danés como modo de llamar la atención del enunciatario: luego de tipiar (ostentar) los signos, escribió: «te preguntarás de dónde saqué esos caracteres, sobre todo el signo $\varnothing$, que no existe en nuestras máquinas de escribir convencionales. Muy simple: de mi fascinación por lo nórdico. $\mathrm{Y}$ de la generosidad del ordenador con que te escribo, que tenía esos caracteres tuyos entre sus secretos» ${ }^{7}$. Por su parte, una referencia valiosa en el proceso de alfabetización informática que ejecutó el autor, y que implicó un reconocimiento mutuo entre él y la máquina «cantante», se encuentra en una carta a la familia Paredes (febrero de 1987). Allí contaba que pasó nueve meses encerrado, escribiendo a mano una novela sobre un pueblo cordillerano, y que después de tipearla y reescribirla dos veces a máquina, y frente a la necesidad de una tercera, decidió comprar un ordenador que contenía un procesador de textos. "Lo que uno escribe va apareciendo en una pantalla de T.V., donde se pueden hacer todas las correcciones que quiera, luego aprietas un botón y el texto, grabado en un pequeño disco, se imprime solo. La novela ha quedado archivada en un solo disco, que puedo volver a corregir cuantas veces quiera, y volverla a imprimir con di- versos tipos de letra» ${ }^{8}$, escribió. Luego de la descripción técnica pasó al impulso creativo, disparador del universo ficcional en su procedimiento: en este caso una fábula humanizante.

También se le puede poner en la memoria un diccionario ortográfico, y te corrige sola los errores (digo sola refiriéndome al ordenador porque le he cambiado el sexo por razones que luego explicaré). El único problema es que con estos aparatos uno se va dando cuenta poco a poco de lo tonto que es, mejor dicho, de lo opa que uno es. Porque siempre meto los dedos [...] donde no corresponde, y entonces ella, que se llama Monse, se pone a gritar como loca, larga unos pitidos histéricos, te prende unas luces y por poco no aparece en la pantalla, con grandes letras, la palabra BOLUDO. [...] Fue Irma la que le puso ese nombre, cansada de oírla "cantar" con sus pitidos, relacionándola con la soprano Monserrat Caballé, una catalana que pesa como 150 kilos y a cada rato aparece cantando en la televisión, como mi ordenador. ${ }^{9}$
Archivo Amstrad. Referencia: [Correspondencia/Amigos/Disco 10/Lene.001].

Archivo Amstrad. Referencia: [Correspondencia/Amigos/Disco 10/Paredes.001].

Archivo Amstrad. Referencia: [Correspondencia/Amigos/Disco 10/Paredes.001]. 
En otro pasaje agregaba: «Veo que la Monse me está haciendo una de sus putadas, me deja espacios en blanco, no sé adónde habré metido esta vez los dedos, porque sin pitar ni nada no alinea bien por la derecha». ${ }^{10}$

El punto cumbre en el uso de este recurso es la carta que le envió a su amigo Héctor David Gatica, a mediados de 1987. E1 valor interpretativo de estos ensayos ¿poéticos? no se restringe al epistolario del Amstrad, sino que podemos vincularlo con los procedimientos de humanización que Moyano ensayaba con los animales en su narrativa de ficción, cuyos ejemplos más acabados son la novela Tres golpes de timbal y los relatos de Un silencio de corchea (Vigna, 2014). En la carta a Gatica, la entidad ordenador va más allá de un nombre, un género y de ejecutar ciertas acciones a la par de los humanos: allí el Amstrad piensa, pide disculpas, valora, sospecha. Es su voz la que comunica, y lo que subyace a ese juego es el reflejo de un sujeto embelesado por la potencia imaginaria y expansiva que inaugura la convivencia con la máquina. Así comienza la carta:

para

\section{HÉCTOR DAVID GATICA}

Querido David: como ves, he puesto tu nombre en el centro, porque te respeto mucho como poeta. Soy el ordenador de Daniel, mi nombre es PCW 8512. Mucho gusto. Él se acaba de ir y me ha dejado ordenado, apretando un botón, que te escriba y te comunique las impresiones que le han producido los libros que le enviaste, impresiones que yo tengo grabadas en mi memoria RAM (se llama así por tratarse de un disco virtual dentro del ordenador, o sea de mí, el PCW 8512, ya puedes llamarme, si así lo prefieres, simplemente PCW, prescindiendo del engorroso número que me identifica según dicen).

Bueno, David, perdóname las digresiones anteriores, simplemente intentaba trabar una relación directa contigo antes de meterme a cumplir las órdenes que me ha dejado grabadas tu amigo Daniel (sé que te quiere, me ha hablado mucho de ti). [...] como él no está (parece que se ha ido a la casa de Carlos Mamonde, no me lo ha dicho pero lo sospecho), voy a dedicarte un par de kilobytes (es decir, unos minutos de tiempo y un espacio en mi memoria electrónica) para entablar una relación directa contigo, imprimiéndote, en líneas centradas $\mathrm{y}$ en un tipo de letra diferente, dos versos tuyos que me han gustado mucho:

Un miedo gatillado

le partió el pensamiento.

¿Te gusta cómo queda? Bueno, me ha costado unos cálculos, pero todo sea por la amistad entre un ordenador y un gran poeta como tú. [...] Bueno, mi querido David, un gran abrazo para ti y Noelia. Tu nuevo amigo, PCW $8512^{11}$

En otros ejemplos, el acto de tipear le ayudaba a recordar ideas, es decir, a combatir el olvido, para luego trasladar ese germen a otros apuntes pre-textuales; en una carta dirigida a Ángeles Prieto Barba decía:

Esto viene a cuento porque los otros días imaginé una historia donde todo lo que se dice en una canción va sucediendo a medida que se lo canta, y se pasa de una situación terrible a otra hermosa, con la misma facilidad con que un verso acaba y otro empieza. No la he escrito, y

\footnotetext{
10 Archivo Amstrad. Referencia: [Correspondencia/Amigos/Disco 10/Paredes.001]
}

11 Archivo Amstrad. Referencia: [Correspondencia/Amigos/Disco 10/Gatica.002]. 
ni siquiera la apunté para hacerlo. Menos mal que el escribirte y mencionarte el asunto me hizo recordar la idea. $^{12}$

Por último, aquí un ejemplo de cómo la nueva velocidad de los dedos en la dactiloescritura, en un ejercicio más amable que en el mecanografiado precedente, donde el error forzaba otras acciones suplementarias, dio como resultado (desde el mismo ritmo en la prosa) ${ }^{13}$ otras variantes de pre-textos preparatorios, quizás más cercanas a la ilusión de estrechar la distancia entre la ráfaga de pensamiento (la imaginación) y la palabra escrita. A partir de una invitación que recibió Moyano para acudir a un evento presidido por los reyes de España, escribió una carta a su hijo Ricardo (25-2-1988) en la que reflejaba la expectativa de asistir, utilizando como motor reflexivo (y como recurso narrativo) su origen mestizo y su torpeza para con los protocolos y formalidades. Allí es posible encontrar el tono de la complicidad familiar, pero también se hace evidente el germen de un relato, un cierto envión narrativo con temática definida, que después de sucedido el evento (la visita al Palacio Real de Madrid) habría de quedar asentado en una crónica que Moyano es- cribió para un periódico español, y que luego expandió en unos 60 folios (según otra carta) bajo el título de Un sudaca en la corte. El destino editorial de esa experiencia mantuvo el título y fue publicado como nouvelle en 2013. Pero, en la carta a su hijo ya se prefiguraba, sin pulir, el registro y el humor que sostuvo la narración desde sus primeros esbozos.

Ante los reyes, según la experiencia, exclusivamente literaria, y mas bien shakespireana, que tengo de ellos, uno tiene miedo hasta de su propio cuerpo. No solo del aspecto seguramente plebeyo de uno (en mi caso, chueco, medio jorobau y fierazo el negro) sino de las vinculaciones que, en una cena, se establecen entre la comida y el cuerpo, es decir, ruidos de masticación, hipos, eructos, bostezos, posibles pedos (sordos y de los otros, de muy mal gusto en una comida familiar o entre amigos, pero terribles en una cena con los reyes y su corte llena de duques y condesas llenas de bucles y caireles). [...]

Entonces me aterra que el rey, teniendo en cuenta de que muchos de los invitados seremos sudamericanos, me pregunte de dónde soy. Cosa que gracias a Dios no hará, porque en cuanto entre al palacio pienso agarrar para el lado de las caballerizas. [...] El problema más gordo va a ser qué le digo, porque nunca se me cruzó por la cabeza nada que tuviera relación con lo que se le pueda decir a un rey. Porque no le voy a decir "soy de La Rioja" ni nada de eso. Tendré que pensar en palabras reales. Las hay a montones, pero como él es rey le importan un carajo y lo aburren. "Majestad" suena a una especie de fiebre, tiene 39 y medio de majestad, dicen, o a nomenclatura para mediciones, grados majestad como los farenheit. También suena a enfermedad, algo así como tener paperas, unas hinchazones de la gran puta vaya a saber en qué parte del cuerpo. Tenemos también "monarca", que es mas bien un grano, algo que sale en la nariz o cerca de las cejas y que todos te ven. En cuanto a "soberano", ni hablar, es un coñac, para colmo ordinario. También

\footnotetext{
12 Archivo Amstrad. 1988. Referencia: [Correspondencia/Literatura/Disco 10/Angeles.007].

13 Para contrastar formas de la sintaxis que se ofrecen con mayor o menor fluidez, basta cotejar los pre-textos preparatorios y borradores de la novela Tres golpes de timbal, confeccionados a mano y en máquina de escribir por Moyano, con ejemplos como este en el epistolario, u otros borradores de cuentos hallados entre los textos del Amstrad.
} 
tenemos trono, cetro, palacio, blasones (parece ropa interior pero cagada), y reyuno, que en Argentina es un caballo con una oreja cortada como señal de que es del gobierno o, lo que es lo mismo, el caballo del comisario, que, al revés de los de mi cuñado, siempre gana las carreras. ${ }^{14}$

Este fragmento sirve como evidencia de los señalamientos metodológicos que Lois (2001) destaca en torno a los materiales pre-redaccionales y también redaccionales: el objetivo es señalar factores determinantes de procesos, o huellas que den cuenta de un descubrimiento de posibilidades y potencialidades. Cartas de esta naturaleza operan como pre-textos preparatorios y en algunos casos como híbridos, teniendo en cuenta elementos que se reiteran en borradores ulteriores: muchas cartas de Moyano han cumplido la función del descubrimiento de la potencialidad de ciertas experiencias. Según Lois (2001), la escritura es huidiza, no unidireccional, y eso impide interpretar determinados pasos como si fueran reglas o pautas. Sí es posible, en cambio, «hablar de un conjunto indeterminado de 'estrategias' variables para cada situación, y es para describir y evaluar estas estrategias que tiene sentido la confrontación escritura-texto» (p. 19).

\section{Guardar para (re)escribir.} Huellas de una alfabetización informática

La segunda arista intenta ejemplificar, a través de la alfabetización en el uso de los programas informáticos: cómo fue en esos años la transición entre los modos de concebir lo material y lo virtual; cómo operó la asimilación de esas máscaras de letras, palabras y frases que comenzaron a aparecer en las pantallas y que antes solo se materializaban cuando alguna tinta manchaba un papel. A través de la palabra del autor, la irrupción de estos dispositivos dio cuenta de cómo se aprehendió una nueva concepción de la memoria: cómo la memoria técnica (a través de un soporte de almacenamiento) se erigió como esa misteriosa salvaguarda de la memoria humana, de la volatilidad de la mente. La bisagra en la rutina y las condiciones de producción de Moyano ejemplifica cómo el acceso a una memoria artificial, menos dubitativa y más fiable que la memoria subjetiva, aceitó el impulso de archivo, optimizando el tiempo y acortando distancias en esa búsqueda de una topografía y una exterioridad. En el caso de Moyano, acentuando la pertinencia de esa confesión derrideana de «escribir para guardar», en su caso adaptada a un escribir para guardar, para reescribir, para guardar, cuantas veces lo permita la energía vital.

El embelesamiento de Moyano, tanto para con los avances en términos de corrección, de variantes lingüísticas y posibilidades gráficas como de «memoria», quedaron demostrados en otros fragmentos de la correspondencia. En una carta a César Llanos (4-1-1988), decía:

Otro de los motivos de mi demora [en responder] ha sido que por temporadas creía haberles contestado, confundido con mi tendencia a elaborar cartas mentales que después no escribo, lo mismo que muchas historias que quedan en ese estado o situación. Ahora tengo un ordenador o computadora, con un procesador de textos que registra todo lo que escribo y lo mete en su memoria, y no me deja equivocarme. De modo que prometo en adelante responder inmediatamente y saber, un par de días después, consultando a la máquina, si la contestación ha sido mental o real, para subsanar el error o distracción en caso de que haya sido lo segundo. ${ }^{15}$

\footnotetext{
14 Archivo Amstrad. Referencia: [Correspondencia/Familia/Disco 11/Ricardo.021].
}

15 Archivo Amstrad. Referencia: [Correspondencia/Amigos/Disco 10/Llanos.001]. 
En otra dirigida a Tata, de 1987, asociaba el ahorro de tiempo y espacio a la hora de corregir y almacenar, con una impronta modernizante:

Como ves, me he modernizado con el asunto escritura, después de haber tenido que pasar en limpio dos veces una novela de 400 páginas. Como no estaba conforme y tenía que volver a hacerlo, me compré el ordenador y procesador de textos, y ahora tengo la novela en un disco, donde puedo hacer todas las correcciones que quiera sin tanto trabajo. Todavía no lo domino bien, es como aprender a manejar un coche, pero aun así es increíble el tiempo que se ahorra. ${ }^{16}$

A Ofelia, en diciembre de 1987 , le contaba que el procesador de texto tenía «un montón de tipos de letras» para ser usadas «según tu ánimo de ese momento», y que automáticamente buscaba y cambiaba palabras, «lo cual es útil para los novelistas como el que suscribe, que a cada rato anda cambiándole el nombre a los personajes. Ahora no tengo que volver a pasar en limpio nada, simplemente corrijo en la pantalla y se acabó», decía Moyano. En esa misma carta (como en otras), daba una muestra de la posibilidad de escribir con los alfabetos cirílico y griego, y terminaba: «¿No te parece una maravilla?».

A Ángeles Prieto Barba, en otra carta de 1987, le confesaba sus trabas en el aprendizaje operativo, con algunas referencias que desde la mirada actual parecen risueñas:

Querida Angeles, no puedo poner dos puntos como siempre en el encabezamiento, porque estoy usando un nuevo programa de proceso de textos que me trajeron de Inglaterra y todavía no le entiendo bien. [...] Ahora, por ejemplo, puedo escribir Gœete usando el diptongo oe, o vitæ, pero no puedo poner dos puntos donde corresponde. Uno puede recurrir a los caracteres griegos, si quiere, para citas eruditas, para eso tiene unas teclas especiales que dicen $-{ }_{-}{ }_{-} \mathrm{o}_{-}$, pero no los dos puntos, en cuya tecla lo que hay es esto @, que no sé qué es.

Y justo cuando quiero copiar una palabra griega, ya que tengo las letras, no sé qué tecla aprieto y mira lo que me sale, nada menos que a $\mathrm{c}$ e $p$

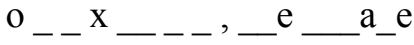
_o__e_epo_e_p, que son, obviamente, caracteres cirílicos, ahora los militares argentinos tendrán una prueba contundente de mi comunismo. ${ }^{17}$

El último fragmento que citaremos, de la misma carta a Ofelia, ha permitido corregir una hipótesis interpretativa sobre su etapa madrileña: específicamente, los motivos que lo llevaron durante esos años a reescribir todos los textos que había producido en Argentina. La sospecha más fuerte, a partir de los testimonios recogidos y de su propio testimonio, era que la condición del «exilio eterno», como él lo llamaba, y la carga nostálgica consecuente, lo empujaron a releer sus textos, a recobrar su experiencia a través del trazo, a repasar la vida a través de la palabra inscrita. Algo que también pudimos analizar en la articulación entre su archivo fotográfico y la escritura de obras como El vuelo del tigre o Un silencio de corchea. Sin embargo, en la carta a Ofelia escribió:

Para distraerme, y aprovechando las ventajas del procesador de textos que tengo, reescribo lo viejo. Prácticamente todo. [...] La reescritura de aquellos trabajos se debe a que, como no conservo los ori-

\footnotetext{
16 Archivo Amstrad. Referencia: [Correspondencia/Amigos/Disco 10/tata.001].

17 Archivo Amstrad. 30-9-1987. Referencia: [Correspondencia/Literatura/Disco10/Angeles.004].
} 
ginales, me he visto obligado a pasarlos otra vez a máquina, es decir, meterlos en la memoria del “computer". He escrito de nuevo cuentos como "La lombriz" y "Los mil días", y ahora estoy con una nueva versión de "El oscuro". Ya que tengo que pasarlo otra vez en limpio, aprovecho para quitarle las tonterías que dije antes y agregarle las que digo ahora. ${ }^{18}$

Esta confesión se repite en otras cartas: como solo tenía el resguardo del papel (vuelve la pregunta: ¿siempre existirá de cara al porvenir?), y nada más que papel, decidió transcribir sus textos a la memoria del ordenador, más fiable. Y como los transcribió, los reescribió. La paradoja, entonces, lleva a confirmar que Moyano no solo reescribió por nostalgia o desarraigo. La exhumación del archivo Amstrad, del epistolario, y por tanto la restauración del secreto (Derrida, 1997), nos permitió generar nuevas categorías para documentos antes desconocidos, pero también cerrar la comprensión de ese obstinado proceso de reescritura que Moyano llevó a cabo durante años. Gracias a la intervención en la intimidad epistolar, pode- mos afirmar que buena parte de la energía que puso en esa obstinación ha sido producida por el entusiasmo que le provocó esta nueva forma de inscribir y de almacenar ideas. Ese contacto con la máquina: la novedad eclipsante del soporte, y de la memoria paralela, parecen haber canalizado esos meses de persistencia frente a la pantalla en pos de ir prefigurando un porvenir superador, para él o para cualquier lector-archivista-interviniente entrometido, transcribiendo y reescribiendo en un mismo movimiento ${ }^{19}$.

Las paradojas de ese progreso, y de la obsolescencia programada, nos comunican con el ambiente técnico actual en que tuvimos que dar la vuelta al camino de la accesibilidad para exhumar los documentos, problematizando la noción de original. El caso Amstrad lleva al interrogante sobre el posible éxito o fracaso de la recuperación de archivos a futuro, y el lugar de lo perdido en los archivos de texto que quedarán y no, en los soportes de almacenamiento, frente a la pesquisa genética. Como afirma Colla (2013), «el uso generalizado de la computadora por parte de los escritores [...] rarifica al extremo la existencia de series de documentos preparatorios: las correcciones, supresiones, las transposiciones se hacen en la pantalla sin dejar rastro alguno de su desarrollo» (p. 111). Moyano decidió transcribir, esto es, generar una segunda versión, porque solo tenía la seguridad del papel: el soporte hasta hoy más estable. Por esto, aunque Derrida en 1997 ya hablaba de la «estabilización en un lugar un poco más seguro» que implicaba salvar los archivos en un disco, quizás sea mejor quitar del aparato conceptual ese deseo o prefiguración de lo estable, al menos en esta materia.

\section{Cierre}

Planteamos el cierre desde dos niveles atravesados por la cuestión técnica. Comenzamos por la posición del autor, su trabajo y su relación con la máquina, para luego pasar a la especificidad del archivo Amstrad y a los aportes metodológicos $\mathrm{y}$ conceptuales que surgieron en sentido más amplio, de cara al porvenir del trabajo con archivos de escritores y a la «administración» de los futuros secretos.

Desde la posición del autor, definiciones como la de Ritchin (2010) explican la esencia de la seducción que la máquina ejer-

Archivo Amstrad. Referencia: [Correspondencia/Amigos/Disco 11/Ofelia.001].

19 Otra hipótesis para la obstinación de la reescritura puede haber sido eso que llamó «escribir como si tocara»: al ensayar nuevas formas sintácticas y usos de la palabra en pos de una nueva musicalidad, Moyano pudo releer todo lo anterior a partir de esa nueva (im)postura. Pero esto no es tan concluyente como su explicación de que el procesador de textos cambió la consideración sobre su memoria, y la discusión del término derrideano sin que eso significara su negación, sino mas bien su exacerbación: «guardo para escribir / guardo para reescribir / reescribo para guardar». 
ce y ha ejercido: el mundo digital es un mundo en el que el ser humano que nació bajo la mirada «mecánica» con frecuencia se siente en desventaja, incluso en medio de la sensación de ventaja que ofrece cada nuevo dispositivo o programa. Según Ritchin, un mundo en el que la máquina se considera inteligente y el ser humano en ocasiones estúpido, tal como se observa en las cartas de Moyano. Esto marca el período transicional en que el desconocimiento de la lógica de funcionamiento de los ordenadores comenzaba a cambiar de signo; como afirmó Ritchin (2010) citando a Eco, a propósito de caracterizar a un viejo ordenador Macintosh según sus «raíces católicas», en sus orígenes desconocidos todo ordenador era «alegre, amigable, conciliador, le decía a los fieles cómo deben proceder, paso a paso, para alcanzar el momento en el que su documento se imprima» (p. 18). Jugando con esa misma idea, Moyano podría haber agregado el castigo que, según sus cartas, el ordenador le imponía cuando se equivocaba al teclear; algo que escapaba a las pretensiones del tipiado mecánico.

Para Ritchin (2010), el «disfraz mimético» del ordenador disminuye la profunda separación entre los medios digitales $y$ sus predecesores. «Basados en segmentos distintos, decisiones calculadas, estrategias binarias y bytes en lugar de átomos», los medios digitales funcionan a partir de un modelo representativo que es capaz de simular todo procedimiento analógico potenciando «el código por encima de la textura» (p. 19) y redefiniendo espacio y tiempo. Pero, a su vez, los medios digitales traducen todo a datos en espera de que un autor o un público (o una máquina) los reconstituya (2010). Esa reconstitución le es ajena a las texturas, lo que lleva a la paradoja de que no hay facilidad y eficacia en el proceso digital si no se cuenta con el respaldo del soporte material. Entre disfraces y representaciones, desde la mirada del autor estamos ante la diferencia entre trazo, o golpe de tinta, y datos.

En relación al objeto, el procedimiento para recuperar y analizar los documentos del Amstrad implicó la ejecución de un método no restringido al soporte fetiche de la crítica genética (manuscritos y papeles), que tampoco surgió como un soporte enteramente virtual. Requerimos la lectura y la migración de datos de un soporte de almacenamiento informático obsoleto, y esa migración se complementó con la necesidad de imprimir los documentos, aun cuando su origen fuera digital; exhumamos por tanto originales, ya que, si no hubiéramos tenido acceso a la migración de datos, el solo éxito en la lectura de los archivos se hubiese limitado a la pantalla de un Amstrad, y a la impresión; solo hubiésemos podido establecer el conjunto de documentos en papel. De hecho, el equipo científico del CRLA decidió imprimir y conservar todo el material, que fue archivado junto a los otros documentos en el Fondo documental Moyano.

Según Derrida, al cambiar la topología y la técnica de consignación, cambia el contenido mismo de un archivo. Entonces, ¿el archivo Amstrad es físico o virtual? Hay argumentos para sostener las dos condiciones, pero todos ellos exaltan la originalidad de los documentos más allá de la unicidad, en la línea de las reflexiones benjaminianas sobre la historia de la reproducción técnica.

A su vez, brotan otras evidencias, como la que hemos mencionado en torno al secreto dentro de la potestad que ostentan los archivistas para sacar a la luz lo oculto: «uno transforma mientras exhuma», ha citado Gerbaudo (1997) del pensamiento derrideano, que definió a la exhumación como el rescate de géneros o textos rechazados, ocultos, desvalorizados. Gerbaudo (2013) amplió esa definición: exhumando se busca «ampliar el horizonte de la investigación literaria a partir de la introducción de materiales y de problemas hasta hace poco inusuales» (p. 72). Esto es lo que nos ha ocurrido, y que ha propiciado un aporte en 
el campo de la investigación crítico-genética a partir de una mirada sociotécnica. Si al hacer lugar a documentos desatendidos algo se mueve, y si cada archivo admite la forma que sus documentos determinan, cada archivo produce su diseño metodológico, y en nuestro caso cada instancia de esa producción llevó a una restauración y re-pérdida del secreto. Dice Gerbaudo (2013):

Si se puede llegar a "perder un secreto" no solo por divulgarlo o romper con un pacto de silencio sino por protegerlo tanto que se tornan inaccesibles las vías para que alguien pudiera rozarlo, hay una relación directa entre la exhumación que interviene sobre documentos que, se intuye, guardan informaciones en camino de olvido, y la revisión de los criterios de selección y ordenamiento de cualquier material. Derrida lo plantea con tono admonitorio: "perder un secreto puede querer decir tanto revelarlo, publicarlo, divulgarlo como guardarlo tan profundamente... que se olvida". [...] En este sentido, un secreto guardado es siempre un secreto perdido. (p. 76).

Entre los aportes conceptuales, en el trabajo con el Amstrad esa paradoja entre lo único y lo seriado que Goldchluk mencionó como propia de cualquier proceso escritural queda desfasada por la obsolescencia de los dispositivos. El hecho de que un escritor «descubra» el ordenador como superación del dispositivo analógico es signo del proceso que hemos vivido acentuadamente en los últimos treinta años: la fantasía de poder corregir en el mismo documento, y de que existan infinitas posibilidades de modificar la escritura in situ y luego copiarla cuantas veces se quiera, prima por sobre el fetiche. Lo «romántico» del trazo, o del golpe de tinta, ha sido subordinado en la rutina escritural a las nuevas velocidades, tanto en lo que se implica en el acto mismo de teclear como en la reproducción. Pero esta afirmación señala el desfase con respecto a los distintos contextos de producción, influenciados por la búsqueda de la superación técnica. El caso Amstrad despliega el valor de lo trunco como signo de las entrañas mismas de esa superación. El fetiche fue aniquilado por la posibilidad de la reproducción infinita y por tanto la unicidad sucumbió, como sucumbieron los restos de aura que podían percibirse (o imaginarse), para que luego el tiempo del consumo reconstruya sus límites y ofrezca el retorno a extrañas formas del fetiche literario con la evolución de los procesadores de texto, que van «dejando atrás» viejas funciones tipográficas, de edición, y soportes de almacenamiento colapsados. En definitiva, van dejando atrás, en pos de una ilusión de velocidad y desdén por los límites, viejas capacidades de memoria. El caso Amstrad se ubica en la mitad de la discusión por la estabilidad; esa condición que entra en crisis, en los archivos, cuando el código digital es el lenguaje imperante. «La ubicuidad acecha», afirma Goldchluk. Siempre y cuando el mercado lo permita.

La exhumación de los textos del Amstrad confirma ese movimiento hacia delante que significa toda inclusión de documentos en un archivo, según Derrida. La exhumación del soporte de almacenamiento ejecutó, en este caso, un doble movimiento: de revisión, según la mirada sociotécnica, de la evolución de los dispositivos informáticos y del efecto de estos en la subjetividad autoral y la rutina creativa, y de construcción del porvenir, donde cada elemento, cada porción del pasado que se incorpora al archivo, y que redefine el objeto y su sostén teórico, crea futuro. Cada nueva inclusión, y por tanto cada nueva intervención, crea futuro desde la potencial ampliación de variantes y significaciones. Cada elemento del pasado que se incorpora a la estructura de un conjunto de documentos produce una alteración en tres dimensiones: modifica los márgenes de lo ya conocido, ampliándolos; modifica sus reverberaciones en el presente 
desde distintas perspectivas disciplinares (hoy la problemática tecnológica es insoslayable), y también se involucra en interpretaciones futuras. El archivo como aval de porvenir que definía Derrida conserva la memoria de otro tiempo para el futuro; el «escribir para guardar», o su inverso, alimentan la fantasía de una acumulación que busca, como dice Gerbaudo (2013), «una reconstrucción im-posible de aquello que inevitablemente se escapa porque tiene lugar una sola vez, única, irremplazable, irrepetible, pero de la que algo resta» (p. 84).

En el presente, esta exhumación permite ver cómo esas huellas tan personales de lo que se escapó hablan de nuestra época, de cómo hemos llegado, y de por qué no es irrisorio pensar que quizás muchas versiones del futuro nos terminen devolviendo al papel. Los trazos y golpes de tinta, y los viejos aparatos, siguen tensionando de modos novedosos las nociones que cimientan nuestras indagaciones, siempre a partir de cada momento de producción.

\section{Referencias}

Archivo Virtual Daniel Moyano. (s.f.). Archivo Amstrad. Francia: Centre de Recherches Latino-américaines, Université de Poitiers. Recuperado de http://www.mshs.univ-poitiers.fr/crla/contenidos/Moyano/Presentacion.html.

Benjamín, W. ([1935] 1987). La obra de arte en la época de su reproductibilidad técnica. En: Discursos interrumpidos I. Madrid: Taurus.

Cabrera, D. (2006). Lo tecnológico y lo imaginario. Las nuevas tecnologías como creencias y esperanzas colectivas. Buenos Aires, Argentina: Editorial Biblos.

Casarin, M. (2012). El itinerario existencial de Daniel Moyano. En: Tres golpes de timbal (edición crítica), Colección Archivos Vol. 64, Poitiers. Francia: CRLA-Archivos.

Chartier, R. (2001). ¿Muerte o transfiguración del lector? Alicante, España: Edición digital. Biblioteca Virtual Miguel de Cervantes. Recuperado de http://bib.cervantesvirtual.com/historia/CarlosV/ recurso1.shtml.

Colla, F. (2010). Escribas, monjes, filólogos, ordenadores. La preservación de la memoria escrita en Occidente. Córdoba: Alción editora.

Colla, F. (2013). Algunas notas sobre archivos virtuales. En G. Goldchluk y M. Pené (Comps.). Palabras de archivo. Santa Fe: Ediciones UNL - CRLA-Archivos. 
Derrida, J. (1997). Mal de archivo. Una impresión freudiana. Valladolid, España: Trotta.

Derrida, J. (2013). Archivo y borrador. En G. Goldchluk y M. Pené (Comps.). Palabras de archivo. Santa Fe: Ediciones UNL - CRLA-Archivos.

Gerbaudo, A. (2013). Archivos, literatura y políticas de la exhumación. En G. Goldchluk y M. Pené (Comps.). Palabras de archivo. Santa Fe: Ediciones UNL - CRLA-Archivos.

Goldchluk, G. (2013). Nuevos domicilios para los archivos de siempre: el caso de los archivos digitales. En G. Goldchluk y M. Pené (Comps.). Palabras de archivo. Santa Fe: Ediciones UNL - CRLA-Archivos.

Goldchluk, G., \& Pené, M. (2013). Instrucciones para archivar un pájaro. En G. Goldchluk y M. Pené (Comps.). Palabras de archivo. Santa Fe: Ediciones UNL - CRLA-Archivos.

Lois, É. (2001). Génesis de escritura y estudios culturales. Buenos Aires: Edicial.

Moyano, D. (1964). La lombriz. Buenos Aires: Nueve 64.

Moyano, D. (1966). Una luz muy lejana. Buenos Aires: Sudamericana.

Moyano, D. (1967). El fuego interrumpido. Buenos Aires: Sudamericana.

Moyano, D. (1968). El oscuro. Buenos Aires: Sudamericana

Moyano, D. (1974). El trino del diablo. Buenos Aires: Sudamericana.

Moyano, D. (1981). El vuelo del tigre. Madrid: Editorial Legasa.

Moyano, D. (1983). Libro de navíos y borrascas. Buenos Aires: Legasa.

Moyano, D. (1988). El trino del diablo y otras modulaciones. Barcelona: Ediciones B.

Moyano, D. ([1968] 2003). El oscuro. Buenos Aires: Ediciones del Sol.

Moyano, D. (2010). Un silencio de corchea. La Rioja: Biblioteca Popular Mariano Moreno.

Moyano, D. ([1989] 2012). Tres golpes de timbal (edición crítica), Colección Archivos Vol. 64. Poitiers: CRLA-Archivos.

Pené, M. (2013). En busca de una identidad propia para los archivos de literatura. En G. Goldchluk y M. Pené (Comps.). Palabras de archivo. Santa Fe: Ediciones UNL - CRLA-Archivos.

Ritchin, F. (2010). Después de la fotografía. México: Serieve-Editorial Océano. 
Vigna, D. (2014). De mulas, burros y perros. Lo animal y el registro del entorno en la prosa y las fotografías del escritor argentino Daniel Moyano. Revue Amerika. Mémoires, Identités, Territoires, (11), 1-16. France: Laboratoire Interdisciplinaire de Recherche sur les Amériques, Université de Rennes. doi: 10.4000/amerika.5739. Recuperado de https://amerika.revues.org/5739.

Vigna, D. (2015). Los desvalidos. Fotografias, textos periodísticos y ficciones de Daniel Moyano. Colección Cuadernos de Archivos (Vol. 2). Poitiers, Francia: CRLA-Archivos. 